\title{
Stop, Collaborate and Listen: An Assessment of Canada's Open Dialogue Implementation Strategy
}

\begin{abstract}
As part of Canada's Action Plan on Open Government, the federal government has adopted a policy activity stream of Open Dialogue to engage stakeholders in the policymaking and regulatory processes. This is an essential step in moving towards a system of decentred collaborative metagovernance to meet the demands of a rapidly changing governance structure, but a policy is only as good as its likelihood of successful implementation. Utilizing the implementation assessment framework of Mazmanian and Sabatier (1981), this paper explores the chances for successful implementation of the Open Dialogue activity stream, concluding that the primary impediment is the structure of the Westminster system. The government's response to this impediment will determine their role in the burgeoning new governance system.
\end{abstract}

\footnotetext{
About the Author(s): Jim Boyle is a second year student in the Master of Public Administration/Juris Doctor joint degree program at Dalhousie University. He completed his BA in Political Science at UBC in 2011, focusing on post-conflict reconstruction and economic development. His research interests include capacity building of least developed region governance structures and how legal systems can affect socioeconomic growth.
} 


\section{Introduction}

In January 2011, The Canadian Radio-television Telecommunications Commission (CRTC) approved the implementation of usage-based billing by internet service providers, threatening to restrict the unlimited internet usage enjoyed by many Canadians. This new regulation was poorly received by the Canadian public. In a digital response organized by OpenMedia.ca, more than 500,000 Canadians tweeted their extreme disapproval with the regulatory decision. Tony Clement, then Industry Minister and the most prolific social media presence in Cabinet, heard the message clearly and was quick to intervene. He reversed the decision, calling the digital response a "seminal moment for social media in Canada" (Clement, cited by Solomon, 2012). Although perspectives will differ regarding the appropriateness of the government overriding a quasi-judicial body's regulatory decision on the basis of citizen discontent, the lesson here is that $21^{\text {st }}$ century federal government communication and decision-making has become dialogic in an unprecedented way.

A year later, Canada entered into the international Open Government Partnership and launched its Action Plan on Open Government, containing a commitment to Open Dialogue. This activity stream promises to increase public participation in policymaking via information technology and social media. Informal digital communication with the citizenry has leaked into government protocol, and is now being formalized as policy. This increased democratization is a key feature of the Harper government's image and the policy certainly resonates with the public, but as Les Pal warns, policy is only as valuable as its execution, and implementation must be taken seriously to avoid failure (Pal, 1997, p. 206).

This article will assess the likelihood of success for the implementation of collaborative governance or 'open-source' government policy in Canada as structured by the Open Dialogue activity stream of Canada's Action Plan on Open Government. The first section of the article will provide a brief synopsis of collaborative government, in general and within Canada. The body of the article will use a framework for implementation analysis developed by Mazmanian and Sabatier (1981) to assess Canada's ability to successfully implement this metapolicy.. The article will conclude optimistically, noting that the shift towards collaborative digital governance is inevitable, but the success of this particular policy is dependent on several variables primarily related to the ability of government departments and agencies to develop the culture change necessary to adapt to $21^{\text {st }}$ century governance and policymaking. 


\section{What is "open-source" government?}

The term 'open-source' government, or wikigovernment, is a portmanteau combining the ideas of non-proprietary information sharing and collaborative coding stemming ' with the notion of $21^{\text {st }}$ century governance, providing a forum for peer production, shared information and social learning to enrich the processes of policymaking and governance (Hubbard \& Paquet, 2010a, 18). In her popular book Wiki Government, Beth Noveck uses these terms interchangeably with collaborative governance, defined by Mark Bevir as "attempts to create and conduct policy that involve the participation of non-governmental and non-traditional political actors... [it] is an interactive process in which myriad actors with various interests, perspectives, and knowledge are brought together" (Bevir, 2009, p. 47). Collaborative governance is closely related to metagovernance, defined by Bevir (2009) as:

the role and actions of the state in securing coordination in the new governance. It suggests that the state now steers and regulates a range of organizations and networks that perform governance. These other organizations undertake much of the work of governing: they implement policies, they provide public services, and at times they even regulate themselves. (p. 131)

These terms have been aggregated by Gilles Paquet to describe the emerging trend in the direction of Canadian governance, in what he terms a move towards decentred collaborative metagovernance (Paquet, 2012). According to Hubbard and Paquet, "increasingly over recent decades, improving Canada's stewardship in the face of accelerated change and increasingly wicked problems has entailed the need to mobilize the collective intelligence of the whole country through the fostering of more participation and of a scintilla of open-source culture" (Hubbard \& Paquet, 2010a, p. 3).

While this prospect has in the past been seen as pure idealism given inevitable financial costs, logistical complexities and loss in efficiency (Doern \& Phidd, 1983, p. 91), the rapid proliferation of web 2.0 technology at the civic and business levels, and its slow-but-steady adoption at the government level, has changed the rules of governance to a point where increased civic participation via collaborative governance is becoming a required reality to which government must successfully adapt.

\footnotetext{
${ }^{1}$ From the realm of information technology - most prominently exemplified by Linux and Wikipedia.
} 
There is a growing body of literature suggesting that increased civic engagement in the policymaking process utilizing backward mapping techniques and collaborative implementation is necessary for the development of 'good governance' (Bevir, 2009; Bang \& Esmark, 2009; Roy, 2006). If it is desirable to have a governance structure that puts effective policy before politics and is highly adaptive, then increasing network governance capacity should be a central goal of government. According to Bang and Esmark, "the kind of political culture and political communication advanced by good governance is premised on the identification of policy projects and the creation of policy publics" (Bang \& Esmark, 2009, p. 17). Good network governance, then, requires civic participation in the policymaking process through the creation of these policy publics; that is, a well-informed and engaged polis that is both reactive and proactive regarding governance initiatives. Good policymaking results from good information, which must be managed under a system "that recognizes that the outcome in our chaotic world is that multiple stakeholders will create a contingent pattern of rules through their diverse understandings and conflicting actions" (Paquet, 2012, p. 6). The goal of government under Paquet's decentred collaborative metagovernance model is to facilitate an inquiring system "capable of ensuring continuous learning and an evolving stewardship apparatus" (Paquet, 2012, p. 7). Under this progressive wikigovernance system, the citizenry takes an active, engaged role in the governance process, both in terms of rapidly providing collective learning experience to the policymaking process, but also by themselves becoming mechanisms for oversight.

Before proceeding, it is necessary to note that open-source government does not equate with direct democracy or plebiscitary democracy; the simple will of the majority electorate does not directly dictate policy or outweigh good policymaking or government practice. Jeffrey Roy (2006) observes that:

the central challenge in any such system lies in aligning the virtual public space with actual decision making within government bodies.

Such alignment does not imply providing a digital means for plebiscites and referendums on all or even most issues (thereby largely circumventing the representational process); rather, it entails a clear demonstration of how elected representatives have made use of such dialogues. (p. 237)

Some scholars warn of the dangers of "over-extend[ing] the sphere of democratic decision making into what ought to be the sphere of individual or corporate decision making" (Korac-Kakabadse \& Korac-Kakabadse, 2001, p. 217). 
However, the basic premise of open-source collaborative government is not to reduce the governance process to a state of digital anarchy, but rather to allow the population an opportunity to participate conveniently, with government guidance, in the governance and policymaking processes (Doberstein, 2012, p. 9). Open-source collaborative government allows governments and citizens to engage in active and informative dialogue based on social learning to produce better policy outcomes.

\section{Why Collaborative Digital Governance?}

The $21^{\text {st }}$ century has presented Canadian governments with unprecedented dynamic challenges requiring solutions and approaches beyond those available to the traditional stratified Westminster public service model. At least three factors have contributed to the formation of an environment where representative parliamentary decision-making supported by periodic elections is no longer sufficient, and digital collaborative governance offers a viable alternative model.

\section{Technological Innovation}

$21^{\text {st }}$ century digital technologies have brought with them significant societal changes; these changes interact with the development of information technologies in a continuing dialectic. Social media, improved information management frameworks, and an increasingly technologically literate population have contributed towards the establishment and growth of networks of communities, organizations and individuals that are connected and communicate in unprecedented ways. The establishment of open-source information networks and wikis has already permeated government institutions. For instance, consultation portals have been launched in several municipalitiesin British Columbia with the establishment of govTogetherBC, and the federal public service has initiated GCPEDIA, a public service open-source forum modeled after Wikipedia (Eaves, 2011, p. 315).

Doern and Phidd (1988) take issue with excessive consultation in the Canadian system, arguing that "it is needed to identify ideas, to learn about problems and, with luck and goodwill, to achieve some solutions" (p. 90), but "too much formal consultation, especially when other instruments of governing (regulation, taxation and spending) are denied politicians, can result in enormous costs, including economic costs"(p. 91). This skepticism may have been appropriate at the time of the authors' writing; however, consultation and collaboration in a Web 2.0 context has eliminated many of these anticipated challenges. 


\section{Receding government capacity for governance}

Frank Ostroff's aphorism "the future is horizontal" has proven true in a number of respects. Canada's hierarchically stratified Westminster style of government premised on linear service delivery, presided over by an accountable minister, is often accused of being inflexible and reluctant to change (Roy, 2006, p. 137). Indeed, many $21^{\text {st }}$ century problems are complex and multidimensional, requiring the horizontal cooperation and coordination of several government departments and agencies, as well as the engagement of civic and private sector organizations (Hubbard \& Paquet, $2010 a$, p. 3). Put simply, the status quo model of government is outdated, and significant updates are required to effectively address $21^{\text {st }}$ century policy problems.

Canadian governments have also experienced a reduced capacity to intervene monetarily due to "chronic public deficits that forced the central government to restructure its operations" (Hubbard \& Paquet, 2010b, p. 163). The Chretien era 'program review' significantly reduced the size and scope of government as dramatic cost-saving restructured and reduced the size of the federal public service (Flynn, 2011 , p. 47). The result of dramatic restructuring was "a smaller public sector, doing fewer things with fewer resources" (Pal, 1997, p. 242). Much more responsibility and authority for addressing policy issues is being devolved across the political spectrum and to non-state actors. The role of government is decreasingly one of paternalist service provision and increasingly one of stewardship and coordination to ensure that public policy objectives are being attained.

More educated electorate/changing political culture

The drive for decentred collaborative metagovernance is a bottom-up process. Changes in socioeconomic circumstances and demographics have created a cultural milieu where change is the norm, and government must keep up in order to retain legitimacy. Technological and economic change, combined with an increasingly heterogeneous demographic and political composition, has created an aggregate political culture that increasingly values self-sufficiency and devolution of governance authority to non-governmental actors (Bang \& Esmark, 2009). This culture shift has been reflected in government. Paquet and Hubbard have stated that this societal change has led to a 'smoothing' of the Westminster model, where horizontality and change culture are increasingly the default settings in government (2010a, p. 91).

Roy (2006) observes that "the first generations of those not knowing a time 
without online commercial, familial, and civic engagements will see no valid reason to exempt the political sphere from this reality" (p. 95). This demographic shift in perspective on communicative norms has created a culture that is more responsive and open to avenues of participation (Noveck, 2009, p. 144).

There is simultaneously a decrease in Canadian confidence in government. A 2012 national survey found that "Canadians were twice as likely to be not confident (18.0 percent) as confident (9.4 percent) in our ability to solve policy issues of concern" (Nanos, 2012, p. 7). This correlates with overall lower levels of political participation. For instance, the past five federal elections had the lowest voter furnout since 1898 (Elections Canada, 2012). In a Samara focus-group study, participants overwhelmingly conveyed feeling "powerlessness" regarding their ability to participate and effect policy change (Ibbitson, 2011). Conversely, a 2012 Fleischman-Hillard national survey found that "(54 percent) of respondents would likely engage more with government if there were ways to participate online" (Torney, 2012).

The lesson here is that citizens' attitudes towards government and governance have changed. Increased network collaboration in the civic and private spheres has not been effectively met with equivalent government measures, alienating large portions of the demographic, particularly young citizens. As evidenced by the Fleischman-Hillard survey (Torney, 2012) and the Samara study (Ibbitson, 2011), the traditional institution of government is becoming less relevant in today's society, which is rapidly evolving. Government must catch up and adapt to this societal change if it is to remain effective. As Bang and Esmark (2009) note, "the emergence of individualism as the dominant culture and of the new communication technologies fit perfectly into the mode of building sociability along self-selected communication networks" (p. 13). If government fails to address this, it risks losing credibility.

\section{The Canadian Approach}

In April 2012, Canada joined the Open Government Partnership (OGP), an international "multilateral initiative that aims to secure concrete commitments from governments to promote transparency, empower citizens, fight corruption, and harness new technologies to strengthen governance" (Open Government Partnership, 2012). OGP is comprised of state and non-state actors in recognition of increasing horizontality and intersectorality in international governance. Eligibility criteria for joining OGP include endorsing the principles of open government as outlined by OGP, as well as taking concrete steps towards initiating an open government action plan, to be reported on annually to OGP. The criteria are intentionally vague, allowing 
individual partners, including governments, businesses and collaborative organizations, to implement policies meeting a minimum standard of 'openness' in ways conducive to their particular circumstances.

In Canada, the output of involvement with OGP and the framework guiding all federal open government policy is Canada's Action Plan on Open Government (CAPOG). CAPOG presents a strategy consistent with the criteria set by OGP, divided into three activity streams geared towards increasing government transparency and connectivity: Open Data, Open Information, and Open Dialogue. It is the third activity stream, Open Dialogue, that pertains directly to increasing collaboration and consultation with Canadian citizens:

Open Dialogue is about engaging Canadians and giving them a strong say in Government policies, programs and priorities. This will be supported by expanding engagement and interaction through Web 2.0 technologies, and will provide Canadians with greater opportunities to participate in the Government, the economy and the democratic process. (Government of Canada, 2012)

The Canadian government has made two commitments within this stream to improve the effectiveness of federal interjurisdictional digital collaboration. The first is Consulting Canadians, a program intended to "simplify access and participation in online consultations by Canadians" and:

develop a standard approach to the use of social media and Web 2.0 by federal departments to augment their engagement activities with citizens and businesses, as well as pilot a crowdsourcing initiative to involve Canadians in developing ideas and solutions for greater online dialogue and engagement on public policy initiatives. (Government of Canada, 2012, p. 8)

The Consulting Canadians website is a joined-up service portal, linking Canadians to relevant information and channels of participation for government consultations across a wide range of government departments, agencies and policy areas, streamlining the collaborative policymaking process. Issues range from energy use regulation to the federal budget, providing Canadians a platform for active engagement with the government. 
The second commitment is Open Regulation, a program designed to ensure that best practices from all sectors are shared with federal regulators to inform efficient regulatory policy. Open Regulation requires federal regulatory agencies to:

electronically post their forward regulatory plans so as to make the regulatory system more predictable and give Canadians and businesses early warning of upcoming changes and the opportunity to engage on regulatory plans. Regulators will also be required to post service standards and policies that clarify when stakeholders can count on receiving guidance in writing. (Government of Canada, 2012, p. 9)

This program is intended to streamline the regulatory policy paradigm by ensuring that affected parties are alerted well in advance of potential changes to regulations, allowing them to prepare. More importantly, it provides affected parties and experts a chance to provide feedback and share relevant information and bestpractices with regulators before regulatory policy is adopted and enforced. This will further allow Canadians to be directly involved in their governance framework in a way once only possible at the local level.

\section{Policy Implementation Assessment}

This section will assess the current state of open-source government and collaborative digital metagovernance initiatives at the Canadian federal level. The policy implementation evaluative framework of Mazmanian and Sabatier (1981) will be adopted to address various facets of the current implementation agenda.

Mazmanian and Sabatier's (1981) conceptual framework of the implementation process is comprised of seventeen independent variables "divided into three broad categories: [a] the tractability of the problem(s) being addressed by the statute; [b] the ability of the statute to favorably structure the implementation process; and [c] the net effect of a variety of 'political' variables on the balance of support for statutory objectives" (p. 6). The likelihood of each variable acting as a potential block for successful implementation is listed in a table (see appendix). In the following section, each of these variables will be evaluated to assess the current state of open-source government policy implementation, and by extension, the successes of and problems facing the Canadian transition from rigid bureaucracy to fluid governance.

It should be noted that Mazmanian and Sabatier published Effective Policy Implementation in 1981; as such their framework for implementation analysis is geared toward mid-20th century realities. Their framework is best applied to traditional 
hierarchical bureaucratic implementation premised on concrete statute and linear authority and accountability. While this premise remains relevant, certain aspects will require some tweaking to apply adequately to Canada's $21^{\text {st }}$ century governance model. Additionally, some variables will be weighted as more contemporarily germane and will therefore be allotted more discussion. Finally, there will be some variables that cannot be adequately assessed given the early stage of implementation.

\section{Tractability of the Problem}

The first variable under this heading is the availability of valid technical theory and technology. The hurdle here is a combination of not only possessing the required technological resources to enact policy, but a cogent theory or developed system for its effective utilization to attain policy goals. Beth Noveck argues that North America has reached a technological zenith where utilization of interconnected network arrangements among national stakeholders is a viable model for governance (Noveck, 2009, p. 146). Web 2.0 technology has flourished in the civic and private sectors; the use of social media and network communication is an all-pervasive force in these spheres. The Canadian government has made concerted efforts since the mid-1990s towards developing its e-government online presence, though primarily on the front of service delivery to the exclusion of enhanced participation (Roy, 2006, p. 230). The challenge is no longer one of developing digital technologies to facilitate collaboration and communication, but rather lies in updating Canada's social and political hardware.

Paquet and Roy (2001) observe that:

the single biggest issue, in the short term, plaguing the government online agenda is not the internal blockages to better coordination, but rather the debate as to how best to proceed with the new development of the new infrastructure required to link on-line governments to its client base across industry and the citizenry. (p. 96)

This is partly due to differences between the organizational logos of the Canadian government and that of collaborative metagovernance. The Westminster model of representative democracy, with its emphasis on linear accountability leading to siloed organizational structures, is in many respects incongruent with the collaborative and participatory mechanisms required for open dialogue and open-source government (Bevir, 2009, p. 145; Roy, 2006, p. 239). 
Stephen Clift (2003) observes that "existing democratic actors have demonstrated their ability to incorporate new technologies and online communication strategies into their own activities and protect their existing interests. They have to in order to survive" (p. 4-5). The government must find a way to effectively converge its mechanisms of accountability with $21^{\text {st }}$ century realities, particularly the growing requirement for increased citizen and stakeholder engagement with, and involvement in, the governance process. The current stage of CAPOG implementation is concerned with research and experimentation, and so this section is currently being addressed. Only when it is completed will citizens and stakeholders be able to tell whether the government will be able to reconcile theory with practice.

The second variable regards the diversity of proscribed target-group behavior. Mazmanian and Sabatier (1981) observe that "the more diverse the behavior being regulated, the more difficult it becomes to frame clear regulations and thus the less likely that statutory objectives will be attained" (p. 8). Given the nature of the CAPOG policy directive being oriented towards metapolicy, there is some ambiguity in this area. The target group is effectively all governance actors in Canada, particularly government departments and agencies. Implementation of this metapolicy requires more than a coordinated effort championed by a Minister to achieve a certain set of outputs or outcomes, but rather necessitates a change in basic operative functions of governance.

The goal of Open Dialogue is to ensure a minimum level of public participation, and through the Open Regulation program, all regulatory agencies will be required to electronically post regulatory plans in advance to allow stakeholders the opportunity to provide feedback (Government of Canada, 2012, p. 9). This will require increased standardization of policy formulation and consultation strategies across government. Without a comprehensive change management strategy, this alteration in everyday operations will likely meet with some resistance, especially among bureaucrats who "avoid public engagement because they believe that policy processes become too slow, costly and unwieldy when they are open to mass public participation (Clarke, 2012, p. 5).

The third variable is the percentage of population whose behavior needs to be changed; in other words, how large a proportion of the total population is the target group. Mazmanian and Sabatier (1981) maintain that "in general, the smaller and more definable (isolatable) the target group whose behavior needs to be changed, the more likely that political support can be mobilized in favor of the program and thus 
the more probable that the statutory objectives can be achieved" (p. 8-9). In the context of establishing effective open-source governance via increasing network collaboration, the target group is effectively the entire population, viewed not as individuals but as communities, organizations and aggregate interests. This fact in itself seems to perplex this variable; however, because the policy under consideration emanates itself from societal change, the situation is less dire than it may initially appear. The societal level change does not emanate from governmental policy, but rather the reverse is true; government policy promoting open dialogue is a reaction to changing social realities, and therefore to some extent the government itself is the target of these policies. While implementing a policy of this scale will be a challenge for coordination, the size of the population in this case does not necessarily hinder its successful implementation.

The fourth variable is closely related to the previous with regards to the extent of behavioral change required of target groups. As previously observed, the change required for effective implementation of this policy is extensive, though much impetus exists already in the private and civic sectors and does not require extensive government direction or control (Roy, 2006, p. 56). Additionally, "public consultations, public opinion research, ministerial roundtables, and the solicitation of expert advice, to name but a few methods of public engagement, have long been integrated into governments' policy-making toolkits" (Clarke, 2012, p. 4). Once again, effective implementation of Open Dialogue at the government level is dependent on successful experimentation to link up the concepts of accountable government with $21^{\text {st }}$ century governance technologies.

In summation, the lessons from this section suggest that implementation of open dialogue will meet institutional and organizational challenges, but success can still be attained if government can combine existing structures and technologies. Metapolicy implementation inherently requires systemic change, and Canada's particularly rigid organizational design is in some ways incongruent with modern, horizontally oriented governance paradigms. This is not to say that implementing Open Dialogue in this environment will be impossible, but to be effective it should be implemented in concert with overarching institutional reform in a culture of experimentation, consultation and feedback. OGP stipulations require that any member's action plan must be implemented with public participation. This rule is not only a requirement for OGP membership, but will prove to be a requirement for providing the learning mechanisms necessary to integrate $21^{\text {st }}$ century governance concepts with the Canadian model. 


\section{Extent to Which the Statute Coherently Structures the Implementation Process}

As a tool for $21^{\text {st }}$ century public policy implementation analysis, this section of Mazmanian and Sabatier's framework is somewhat outdated. Their definition of statute reads, "From the perspective of our framework, a statute constitutes the fundamental policy decision being implemented in that it indicates the problem(s) being addressed and stipulates the objective(s) to be pursued. It also has the capacity to 'structure' the entire implementation process" (Mazmanian \& Sabatier, 1981, p. 10). For the purpose of this analysis, Canada's Action Plan on Open Government will be used in place of statute, as it fulfills most of the criteria outlined above. Though the Open Government Partnership's 'Articles of Governance' ultimately inform and provide a minimum framework of obligations for CAPOG, they carry no real authority in Canada beyond their applications to CAPOG. For this reason, OGP will not be addressed in this section.

The fifth variable is the precision and clear ranking of statutory objectives. The need for well-structured and unambiguous policy architecture is well recognized in the literature as a fundamental aspect of effective policy implementation (Mazmanian and Sabatier, 1981, p. 10; Edwards and Sharkansky, 1978, p. 297). It is also recognized as an important aspect of public sector accountability and is key to successful implementation. Put frankly by David Stuewe with reference to communicating clear organizational vision, "if you don't know where you're going, you're not going to get there" (Stuewe, 2012). As Canada's Open Dialogue implementation strategy is informed by a vague action plan regulated by an even less detailed international commitment, it would be convenient to immediately dismiss the federal government's implementation strategy as doomed to failure. This peculiar and revolutionary policy, however, should not be subject to quantification in the same way as many traditional, output oriented policies. The first year of the three-year implementation strategy for CAPOG is concerned primarily with information gathering, consultation and experimentation (Government of Canada, 2012). Far from being a cause for concern, Paquet asserts that experimentation is necessary to develop the critical collaborative governance mechanisms required to move forward in the $21^{\text {st }}$ century, and the fear of the unstructured nature of such policy directions has led to a lack of experimentation, resulting in preservation of our present archaic governance system (Hubbard \& Paquet, 2010a, p. 179). For Open Dialogue policy, there is only an idea of what the system will finally look like, and the government, in collaboration with non-government sectors, is working towards developing an effective model for collaborative 
metagovernance. It is likely that years two and three of the implementation strategy will contain more concrete ranking of objectives as the necessary policy architecture to achieve the policy's intentions become increasingly evident.

The sixth variable is the validity of the causal theory incorporated into the statute. An "adequate causal theory requires (1) that the principal causal linkages between governmental intervention and the attainment of program objectives be understood and (2) that the officials responsible for implementing the program have jurisdiction over a sufficient number of the critical linkages to actually attain the objectives" (Mazmanian and Sabatier, 1981, p. 11). There appears to be sound causal linkages in the Open Dialogue stream of CAPOG. As stated in the previous section, the mechanisms of implementation are not finalized, requiring sweeping administrative as well as cultural change for success, though it would appear that government need only worry about the latter, as the former is already well on its way towards becoming a culture of collaboration (Noveck, 2009). Increasing government openness by increasing collaboration and consultation is intuitively logical, and the policy is being championed by the Treasury Board. This body is a central component of government's technostructure with extensive control over critical links that will increase government's engagement with the citizenry via horizontal standardization, as well as financial incentives to restructure departmental policymaking processes.

The seventh variable is the availability of financial resources. Doberstein (2012) has recognized that "one of the core elements of metagovernance is resourcing" (p. 10) in the form of enabling resources to allow government and non-government stakeholders the ability to successfully utilize technological and human resources for effective network collaboration. Treasury Board Secretariat's 2012-2013 Report on Plans and Priorities places CAPOG within its modernizing government project (Treasury Board, 2012). Its program activities include Management Frameworks and People Management, which, for the 2011-2012 fiscal year, have a planned expenditure of respectively $\$ 80,181,000$ and $\$ 66,715,000$. Planned spending for the next three fiscal years is over $\$ 50$ million for each program activity. It appears that this policy will not suffer from a lack of financial resources.

The eighth variable is the extent of hierarchical integration within and among implementing institutions. Under the traditional Westminster system premised on vertical accountability, horizontality presents significant challenges for service delivery and can, if ineffectively managed, hinder successful implementation. The problem persists with the implementation of Open Dialogue as it requires the compliance not only of vertical and horizontal government actors, but external stakeholders. This is 
partially counteracted by placing the steering and champion responsibilities for the action plan in the hands of the Treasury Board, and specifically in the office of Treasury Board's President Tony Clement. Controlling the dispersion and flow of financial resources among departments and agencies provides a powerful compliance incentive.

The ninth variable is the extent to which decision-rules of implementing agencies are supportive of statutory objectives. This involves providing clear objectives, reducing veto points and providing adequate compliance incentives (Mazmanian and Sabatier, 1981, p. 12). As this policy will be implemented government-wide and will require alterations to the policy formulation methodologies of regulatory agencies and departments, the implementation experience will differ depending on organizational culture. It is to be expected that some regulatory agencies and managers will resist the change. Ironically, the ministerial hierarchy will help in the initial phases of Open Dialogue implementation due to the direct lines of accountability flowing to cabinet. Additionally, as mentioned in the previous point, placing overall project management with Treasury Board will help ensure that managers intent on their organization's success will comply.

The tenth variable describes the commitment of implementing agencies and officials. Building commitment across government in any policy area can be achieved by effective use of vertical structures, but the strategic apex must be itself completely committed to the realization of the policy objective. There is some partisan criticism of the Harper government regarding its commitment to openness, however, for this policy it is too early to determine with any certainty whether the Harper government is paying lip-service, or whether its commitment will translate into similar and concrete enthusiasm in the implementing agencies.

The eleventh variable is the extent to which the target beneficiaries of a government policy have formal access to participation or redress regarding the policy implementation. As directed by OGP Consultation Guidelines, the implementation process must include nation-wide consultations including online and in-person meetings. CAPOG itself will be executed with extensive citizen participation, which, according to Mazmanian and Sabatier (1981), will increase the likelihood of the policy's implementation success (p. 14).

\section{Nonstatutory Variables Affecting Implementation}

Government does not exist in a vacuum, and the success of policy implementation extends well beyond the capacity of government to orchestrate and 
execute policy through its executive hierarchy. This section of the analytical framework is particularly pertinent to the discussion of open-source government policy implementation; a policy that by its very definition requires substantial cooperation and input from non-governmental actors.

To some extent, the challenges presented in this section resemble those elucidated by John Kotter (1996) regarding change management. Though this article does not view policy implementation as strictly a project management challenge, to the extent that policy implementation of this scope requires large-scale systemic and organizational change affecting stakeholders across all sectors, some lessons can be derived from Kotter's analysis. Dutil et al. observe that "the open-source-inspired model of content provision and constant peer review fuel constant adaptation and quality control in a manner that the traditional forms of corporate specialization and supervision can simply not generate" (Dutil, Howard, Langford and Roy, 2010, p. 133). The shift to an open and collaborative form of policymaking and governance carries with it the implications of creating a change-culture; however, as Kotter (1996) asserts, the challenge is in instigating change and building commitment. After these foundations are laid, each subsequent step in change implementation becomes more fluid, as "open source is both a precursor of and a proxy for more open government" (Roy, 2006, p. 57). This heavily echoes Paquet's (2012) notion of the autopoietic state, as the move towards collaborative metagovernance, is "likely to elicit a sort of guidance - or automatic pilot - capable of ensuring continuous learning and an evolving stewardship apparatus" (p. 7).

The twelfth variable pertains to the social, economic and technological milieu in which the policy implementation paradigm must operate. Within the context of implementing Open Dialogue, this is the most important determinant of success. As discussed in the first part of this paper, Canada has reached a point of development where increased collaboration and decentred governance are not just viable, but increasingly necessary to adequately address multidimensional policy problems. The time has come for collaborative governance.

The thirteenth variable concerns the amount and continuity of media attention to the policy. Initial media coverage focused on positive aspects of CAPOG, but little coverage has been sustained since its unveiling in April 2012. A good deal of media attention, primarily through watchdog organizations such as Democracy Watch and OpenMedia.ca, has been devoted to criticisms of the Harper government's level of commitment to CAPOG, primarily in the form of cynicism about its overall 
transparency. Until the policy is implemented fully across all sectors of government, it will be difficult to assess the media's reaction.

The fourteenth variable concerns the degree and variation by time and jurisdiction of public support for the policy objectives. Community based participatory projects typically breed "commitment and engagement amongst members who not only choose to partake in this creative process but also nurture an attachment to its principles and outputs" (Dutil et al, 2010, p. 133). This seems to be confirmed quantitatively, as demonstrated by the positive public response to the prospect of increased participation in governance found by Fleishman-Hillard (Torney, 2012). Currently, Open Dialogue seems to enjoy popular support among the public; however, related to the thirteenth variable, this could be subject to change. The secrecy of the Harper government is seen as counterproductive towards the implementation of open government initiatives, and, depending on future public perceptions of the government's commitment, could affect successful implementation. If the public is cynical, levels of participation will be low, undermining the intent of the policy action. The Harper government will have to rectify its image to ensure that the public feel that their participation will be meaningful and not merely a charade.

The fifteenth variable concerns the extent to which implementers and proponents can maintain public support and interest over time. This is a Sisyphean challenge considering the length of time effective implementation takes, and the tendency of the public and the media to quickly turn their attention towards new, high profile issues, rather than focus long-term on specific issues. Mazmanian and Sabatier (1981) note that "opponents can generally intervene more actively over a longer period of time than proponents" (p. 18) due to the comparatively smaller amount of effort required to resist rather than implement change. A project like Open Dialogue, however, is unlikely to lose public support due to its citizen-inclusive nature; whether it can hold their attention and engage them is a different matter. Kotter (1996) asserts that to maintain commitment, there must be short-term wins in the context of change; the government will have to demonstrate positive outcomes from its online consultations and citizen engagement. For most advocacy coalitions, civic organizations and the business community, interest is unlikely to wane, except for reasons noted in the previous point.

The sixteenth variable regards the continued support for policy objectives among sovereigns. This section is difficult to navigate with the current government; while the Harper government has taken a consistent stance in favor of transparency, 
openness and collaboration, recent experience has questioned whether its stated commitment is in earnest. At least in image, the Harper government is fully supportive of the issue, but only time will tell if the intent of Open Dialogue activity is to develop real openness and inclusiveness, or for electoral gain.

The seventeenth and final independent variable is the commitment and leadership skill of implementing officials. As noted by Craft (2011), "although parliament and legislators pass laws regarding the broad strokes of regulations, the real control over how those regulations will take shape falls to the public service" (p. 59). As this policy will be implemented across government, there will be a great degree of variation here, and certainly some resistance to change will be expected. From the perspective of individual government organizations, success is dependent on effective leadership of change management. To that extent, government must be able to rely on its senior public servants to take the steps outlined by Kotter (1996) to create a sense of urgency necessary to instigate a sustainable change-oriented organizational culture. As noted by Roy (2006), "The ability of government to more effectively reach out to and engage with citizens in consultative and participative mechanisms hinges on both the individual skills sets and managerial structures and cultures shaping the actions of public servants" (p. 85). The government will have to incent compliance among its public service managers, without whom the policy implementation will founder.

\section{Conclusion and Going Forward}

The successful implementation of Open Dialogue requires the government to view its Action Plan on Open Government not as a program to be implemented linearly as part of a business-as-usual policy implementation strategy, but as an attempt at long-term reform of the organizational design and political culture of the federal government. Noveck (2009) observes that "the success of collaborative governance is, in large measure, a question of creating a culture that wants to move away from the single point of failure" (p. 147). Effectively implementing consultative and collaborative governance mechanisms via policy directive requires systemic cultural change in government. It is therefore critical that any earnest implementation policy must incorporate a change management strategy.

Ultimately, if Paquet's thesis holds true, the organizational structures of the Westminster system will have to be reorganized if decentred collaborative metagovernance is to be realized. Real dialogue requires real opportunity for effecting political change through policy implementation, which can be achieved at 
any level of government, by external stakeholders, or through public-private partnership arrangements.

While use of traditional Westminster hierarchical coercion may be useful initially in ensuring departmental compliance with consultation objectives, the growth of the open-source system will eventually clash with the rigidity of Canada's public sector system. Increased civic participation in decision-making leads to increased civic participation in governance, which is likely to increase alternative service deliveries from non-government sectors. The success of Open Dialogue seems certain. Whether the federal government is the primary driver of this success, or whether its current impetus will carry it to fruition regardless of the government is difficult to predict. Current indications, however, suggest that the government has the capacity to at least spearhead the beginning of the process. It is entirely possible that the future of collaborative governance will see it taking a life of its own; government will have to work hard to control the reigns of governance. If we are to learn from the experience with the CRTC addressed at the beginning of this article, citizens are ready to take an active role in governance. Whether they have the tools to do this effectively will depend on the successful implementation of this policy. 


\section{References}

Bang, H. \& Esmark, A. (2009). Good governance in network society:

Reconfiguring the political from politics to policy. Administrative Theory and Praxis, 31 (1), 7-37.

Bevir, M. (2009). Key concepts in governance. Los Angeles: SAGE.

Canada Treasury Board Secretariat. (2012). Treasury Board of Canada Secretariat Report on plans and priorities 2012-2013. Retrieved from http://www.tbssct.gc.ca/rpp/2012-2013/inst/tbd/tbd01-eng.asp.

Clarke, A. (2012). Open dialogue and the Government of Canada's use of social media: Bureaucratic barriers to democratic engagement in the digital era. Canadian Political Science Association Annual Conference 2012, Edmonton. Retrieved from the Google Scholar database.

Clift, S. (2003). E-democracy, e-governance and public net-work. Publicus, 1 (1). Retrieved from http://www.publicus.net/articles/edempublicnetwork.html.

Craft, J. (2011). Public servants control government. In R. P. Leone and F. L. K. Ohemeng (Ed.), Approaching public administration: Core debates and emerging issues. (pp. 54-65). Toronto: Emond Montgomery Publications.

Doberstein, C. 'Metagovernance' of urban governance networks in Canada: In Pursuit of legitimacy and accountability. Canadian Political Science Association Annual Conference 2012, Edmonton. Retrieved from www.cpsaacsp.ca/papers-2012/Doberstein.pdf.

Doern, G. B. \& Phidd, R. W. (1983). Canadian public policy: Ideas, structure, process. Toronto: Methuen.

Dutil, P. A., Howard C., Langford J. \& Roy J. (2010). The service state: rhetoric, reality and promise. Ottawa: University of Ottawa. 
Eaves, D. (2011). Using the tools of the $21^{\text {st }}$ century: Open data and wikis. In R. P. Leone and F. L. K. Ohmeng (Ed.), Approaching public administration: Core debates and emerging issues. (pp. 309-317). Toronto: Emond Montgomery Publications.

Edwards, G. C. \& Sharkansky, I. (1978). The policy predicament: Making and implementing public policy. San Francisco: W. H. Freeman.

Elections Canada. (2012). Voter Turnout at Federal Elections and Referendums. Retrieved from http://www.elections.ca/content.aspx? section=ele\&dir=turn\&document=index \&lang $=e$

Flynn, G. L. (2011). Politicians control government. In R. P. Leone and F. L. K. Ohmeng (Ed.), Approaching public administration: Core debates and emerging issues. (pp. 43-53). Toronto: Emond Montgomery Publications.

Government of Canada. (2012). Canada's Action Plan on Open Government. Retrieved from www.open.gc.ca/open-ouvert/ap-pa-eng.pdf

Hubbard, R. \& Paquet, G. (2010a). The black hole of public administration. Ottawa: University of Ottawa.

Hubbard, R. \& Paquet, G. (2010b). The case for decentralized federalism. Ottawa: University of Ottawa.

Ibbitson, J. (2011, Oct 18). The alarming decline in voter turnout." The Globe and Mail. Retrieved from http://www.theglobeandmail.com/news/politics/the-alarming-decline-in-voterturnout/article4247507/>

Korac-Kakabadse, A. \& Korac-Kakabadse, N. (2001). Information technology's impact on the quality of democracy. In R. Heeks (Ed.), Reinventing government in the information age. (pp. 211-228). New York: Routledge.

Kotter, J. P. (1996). Leading change. Boston, MA: Harvard Business School. 
Mazmanian, D. A., \& Sabatier, P. A. (1981). Effective policy implementation. Lexington, MA: Lexington.

Nanos, N. (2012). Canadians rate highly the issues close to their day-to-day lives. Policy Options. Institute for Research on Public Policy. Retrieved from www.irpp.org/po/archive/aug12/nanos.pdf.

Noveck, B. S. (2009). Wiki government: How technology can make government better, democracy stronger, and citizens more powerful. Washington, D.C.: Brookings Institution.

Open Government Partnership. (2012). OGP consultation guidelines. Retrieved from http://www.opengovpartnership.org/sites/www.opengovpartnership.org/files/p age_files/OGP\%20Public\%20Consultation\%20Guidlines.pdf.

Pal, L. (1997). Beyond policy implementation: Public issue management in turbulent times. Scarborough, ON: Nelson.

Paquet, G. (2012). Slouching toward a relatively stateless state. Optimum Online, 42(2). Retrieved from http://www.optimumonline.ca/print.phtml?id=414.

Roy, J. (2006). E-government in Canada: Transformation for the digital age. Ottawa: University of Ottawa.

Solomon, H. (2012, Feb 17). Social media pushes government, says Clement. IT World Canada. Retrieved from http://www.itworldcanada.com/news/socialmedia-pushes-government-says-clement/144906.

Stuewe, D. (2012, Nov 28). Roles, responsibilities \& relationships. PUAD 5100. Dalhousie University School of Public Administration, Halifax. 28 Nov. 2012. Lecture.

Torney, J. (2012, Jan 25). Government 2.0: Why social media makes sense. Fleishman-Hillard. Retrieved from http://fleishman.ca/2012/01/government-2-0why-social-media-makes-sense/ 
Appendix: Likelihood of each variable acting as a stumbling block for successful implementation

\begin{tabular}{|l|l|l|l|}
\hline Variable & Low & High & Indeterminate \\
\hline $\begin{array}{l}\text { 1. Availability of valid technical theory } \\
\text { and technology }\end{array}$ & X & & \\
\hline $\begin{array}{l}\text { 2. Diversity of proscribed target group } \\
\text { behavior }\end{array}$ & & & X \\
\hline $\begin{array}{l}\text { 3. Percentage of population whose } \\
\text { behavior must change }\end{array}$ & & $X$ \\
\hline $\begin{array}{l}\text { 4. Extent of behavioral change required } \\
\text { for target group }\end{array}$ & & $X$ \\
\hline $\begin{array}{l}\text { 5. Precision and clear ranking of } \\
\text { objectives }\end{array}$ & $X$ & & \\
\hline 6. Validity of causal theory & $X$ & & \\
\hline 7. Availability of financial resources & $X$ & & \\
\hline $\begin{array}{l}\text { 8. Extent of hierarchical integration } \\
\text { within and among implementing } \\
\text { institutions }\end{array}$ & $X$ & & \\
\hline $\begin{array}{l}\text { 9. Extent to which decision-rules of } \\
\text { implementing agencies are supportive } \\
\text { of statutory objectives }\end{array}$ & $X$ & & \\
\hline $\begin{array}{l}\text { 10. Commitment of implementing } \\
\text { agencies and officials }\end{array}$ & & $X$ & \\
\hline $\begin{array}{l}\text { 11. Extent to which target have formal } \\
\text { access to participation regarding } \\
\text { implementation }\end{array}$ & $X$ & & \\
\hline $\begin{array}{l}\text { 12. Social, economic and } \\
\text { technological milieu }\end{array}$ & & & \\
\hline 13. Amount of media attention & & \\
\hline $\begin{array}{l}\text { 14. Degree and variation by time and } \\
\text { jurisdiction of public support for the }\end{array}$ & & $X$ & \\
\hline
\end{tabular}




\begin{tabular}{|l|l|l|l|}
\hline policy objectives & & & \\
\hline $\begin{array}{l}\text { 15. Extent to which implementers and } \\
\text { proponents can maintain public } \\
\text { support and interest over time }\end{array}$ & $X$ & & \\
\hline $\begin{array}{l}\text { 16. Continued support for policy } \\
\text { objectives among sovereigns }\end{array}$ & & & $X$ \\
\hline $\begin{array}{l}\text { 17. Commitment and leadership skill of } \\
\text { supportive implementing officials }\end{array}$ & & & $X$ \\
\hline
\end{tabular}

